\title{
Energy Efficiency and Emissions Analysis of Ammonia, Hydrogen, and Hydrocarbon Fuels
}

\author{
Yuegu Wang, Songsheng Zheng, Zhaolin Wang \\ College of Energy, Xiamen University, Xiamen, China \\ Email address: \\ belle_yue@163.com (Yuegu Wang), songsheng@xmu.edu.cn (Songsheng Zheng), forestwang@xmu.edu.cn (Zhaolin Wang)
}

\section{To cite this article:}

Yuegu Wang, Songsheng Zheng, Zhaolin Wang. Energy Efficiency and Emissions Analysis of Ammonia, Hydrogen, and Hydrocarbon Fuels. Journal of Energy and Natural Resources. Vol. 7, No. 1, 2018, pp. 47-53. doi: 10.11648/j.jenr.20180701.17

Received: April 20, 2018; Accepted: June 6, 2018; Published: June 20, 2018

\begin{abstract}
This paper compares some typical fossil fuels with carbon-free fuels from aspects of combustion-related properties, energy efficiency and emissions. It is based on the assumption that the fuel of interest is completely combusted. The comparison indicators include species of exhaust gases, wasted heat of emissions and the quantities thereof. It is found that in spite of the weakness of lower volume energy density of ammonia than gasoline, diesel and methane, the lower corresponding air-fuel ratio of ammonia compromised this weakness. From the comparison of total emissions by mass, it is found that combustion of ammonia generates a much smaller amount of total emissions than the combustion of the same kilogram of hydrogen, gasoline, diesel, methane, and ethanol. Although combustion of hydrogen does not generate $\mathrm{CO}_{2}$, the total emissions by mass are much larger than other fuels and is 5 times greater than ammonia per unit mass of fuel. Besides, the total amount of emissions of these fuels is similar when producing the same amount of combustion heat. It is concluded that ammonia is a very promising fuel that not only generates fewer $\mathrm{CO}_{2}$ emissions, fewer total emissions, but also performs high energy efficiency.
\end{abstract}

Keywords: Fuels, Ammonia, Combustion Emissions, Hydrogen

\section{Introduction}

With rapid development of the world economy and continuous improvement of human living standards, problems of depletion of oil resources and emissions of greenhouse gases are becoming increasingly serious, and seeking alternative fuels is brought to public attention. According to the statistics from US Environmental Protection Agency, the transportation industry depends primarily on petroleum fuels and consumes $57 \%$ of the world energy. Environmental deterioration issue caused by the combustion process of fossil fuels beyond dispute becomes more and more serious. At a production development rate of $5 \%$, conventional petroleum and crude oil resources may last only 51 years as assessed in 2014 [1]. Therefore, searching for alternative fuels should be identified without delay for the whole world.

When it comes to the fossil fuels which consist predominantly of hydrocarbon chains, various exhaust pollutants are generated, including carbon monoxide $(\mathrm{CO})$, hydrocarbon $(\mathrm{HC})$, nitrogen oxides $\left(\mathrm{NO}_{\mathrm{X}}\right)$ and particulate matter (PM), among other products. $\mathrm{CO}_{2}$ as a complete combustion product contributes to global temperature increase. Alternative fuel utilization is expected to provide easy storage and transport, energy security, high energy density and low greenhouse effect. Hydrogen has been recognized potentially as the promising fuels which can be burned in an environmentally friendly way [2-4]. Although hydrogen is an ideal fuel used in internal combustion engines with respects to clean exhausted gases, it is difficult to store at very high pressure and has a low energy density per unit of volume. Referring to the characteristics of storage and transportation, liquid hydrogen is usually stored at $-253^{\circ} \mathrm{C}$ and its liquefaction is a high energy consumption process and its storage requires a high-level container material.

Much work has been done to search alternative fuels for powering transportation vehicles. Ammonia as a hydrogen energy carrier can be utilized in almost all types of combustion engines, e.g., gas turbines and directly in fuel cells, as a sustainable fuel with only small modifications. This is a very attractive advantage compared to other alternative fuels [5-7]. Furthermore, several ammonia combustion mechanisms have been proposed in these researches [8-10].

Extensive analysis of ammonia or hydrogen combustion 
mechanism and energy per unit of storage, in comparison with other conventional fuels, has been conducted by other researches [11-14]. However, successful application of alternative vehicle fuels should be grounded in detailed understanding of its theoretical combustion performance analysis in thermodynamics. This paper principally is devoted to quantitatively elaborating the emissions of combustion for per unit energy gain from the combustion of different types of vehicle fuels. Several comparison indicators include species of exhaust gases and quantities thereof are discussed. Besides, apart from the emissions quantitative analysis, this paper also explains wasted heat taken away by exhaust gases at different temperature. It is expected that the comparison allows a better understanding of ammonia as alternative vehicle fuels from the aspects of combustion-related properties and emissions condition.

\section{Methodology}

Emissions calculation about ammonia, hydrogen and other

$$
\begin{gathered}
\mathrm{NH}_{3}+0.75 \mathrm{O}_{2}+2.82 \mathrm{~N}_{2} \rightarrow 1.5 \mathrm{H}_{2} \mathrm{O}+3.32 \mathrm{~N}_{2} \\
\mathrm{H}_{2}+0.5 \mathrm{O}_{2}+1.88 \mathrm{~N}_{2} \rightarrow \mathrm{H}_{2} \mathrm{O}+1.88 \mathrm{~N}_{2} \\
\mathrm{CH}_{4}+2 \mathrm{O}_{2}+7.52 \mathrm{~N}_{2} \rightarrow \mathrm{CO}_{2}+2 \mathrm{H}_{2} \mathrm{O}+7.52 \mathrm{~N}_{2} \\
\mathrm{C}_{2} \mathrm{H}_{5} \mathrm{OH}+3 \mathrm{O}_{2}+11.29 \mathrm{~N}_{2} \rightarrow 2 \mathrm{CO}_{2}+3 \mathrm{H}_{2} \mathrm{O}+11.29 \mathrm{~N}_{2} \\
\mathrm{C}_{8} \mathrm{H}_{18}+12.5 \mathrm{O}_{2}+47 \mathrm{~N}_{2} \rightarrow 8 \mathrm{CO}_{2}+9 \mathrm{H}_{2} \mathrm{O}+47 \mathrm{~N}_{2} \\
\mathrm{C}_{12} \mathrm{H}_{26}+18.5 \mathrm{O}_{2}+69.56 \mathrm{~N}_{2} \rightarrow 12 \mathrm{CO}_{2}+13 \mathrm{H}_{2} \mathrm{O}+69.56 \mathrm{~N}_{2}
\end{gathered}
$$

\subsection{Clean Emissions Degree Evaluations}

In typical evaluation approaches of the emissions, the mass of carbon monoxide (CO), hydrocarbon ( $\mathrm{HC})$, nitrogen oxides $\left(\mathrm{NO}_{\mathrm{X}}\right)$ and particulate matter $(\mathrm{PM})$ reflect the relative importance in determining whether the fuel is clean. However, total emissions and carbon dioxide emission by mass of fuels, air and combustion heat are used in this study to evaluate the emissions properties of fuels. The three indicators are parameters that describe the different evaluating objectives to a certain attribute. When the value among different fuels in the same indicator is high or lower, i.e., the value of it illustrates that this fuel produces relative clean or pollute emissions.

$$
\begin{gathered}
\alpha_{e m}=\frac{m_{e m}}{m_{f u e l}} \\
\beta_{e m}=\frac{m_{e m}}{m_{\text {air }}}
\end{gathered}
$$

Where $\alpha_{e m}$ is the emissions produced by the same amount of fuels; $m_{e m}$ and $m_{f u e l}$ present the mass of total emissions and carbon dioxide emission of fuels respectively. The $\beta_{e m}$ is the emission generated by the same amount of theoretical air requirement during the complete combustion process.

$$
\gamma_{e m}=\frac{m_{e m}}{m_{f u e l} \cdot L H V}
$$

Where $\gamma_{e m}$ is the total emissions produced by the same amount of heat; in the same way, $m_{e m}$ present the mass of total emissions or the carbon dioxide of these fuels, $L H V$ is the Lower heating value of fuels, and it is given in Table 1.

\subsection{Combustion Energy Efficiency}

$$
\begin{gathered}
Q_{\mathrm{em}}=\sum_{i=1}^{n} \int_{T_{1}}^{T} c_{p_{i}} d T \\
{\left[c_{p}\right]_{N_{2}}=\frac{\int_{T_{1}}^{T}(1.03+0.00008955 \mathrm{t}) d t}{T-T_{1}}} \\
{\left[c_{p}\right]_{H_{2} O}=\frac{\int_{T_{1}}^{T}(1.833+0.0003111 \mathrm{t}) d t}{T-T_{1}}} \\
{\left[c_{p}\right]_{\mathrm{CO}_{2}}=\frac{\int_{T_{1}}^{T}(0.8725+0.0002406 \mathrm{t}) d t}{T-T_{1}}}
\end{gathered}
$$


Where $n$ is the kind of exhaust gases including carbon dioxide, nitrogen and water at gaseous state; $Q_{e m}$ is the wasted heat taken away by exhaust gases at different temperature, $\mathrm{kJ} / \mathrm{kg}$; $\mathrm{T}$ is the temperature of emissions, ${ }^{\circ} \mathrm{C} ; T_{1}$ is the temperature of air, and it is 25 degree centigrade; $c_{p i}$ is the constant pressure heat capacity of gaseous state water, carbon dioxide and nitrogen [15].

Energy efficiency is one of the most important features of fuels at combustion process. The efficiency is influenced by not only the combustion conditions but also the heat taken away by emissions.

$$
\eta=\left(1-\frac{Q_{\mathrm{em}}}{Q_{t}}\right) \times 100 \%
$$

Where $\eta$ is energy efficiency of fuels at combustion process; $Q_{e m}$ is the heat taken away by exhaust gases at different temperature; $Q_{t}$ is the total heat combustion generated by per unit of fuels.

\section{Emissions Analysis}

This section first presents the physical and chemical characteristics of ammonia, hydrogen and other conventional fuels. Then environmental impacts of various fuels are comparatively assessed including total amount of exhausted gases and carbon dioxide.

\subsection{Chemical and Thermodynamic Properties}

Table 1 presents the physical and chemical properties of the conventional and alternative fuels. Compared with hydrocarbon fuels, both ammonia and hydrogen have a higher octane number which suggests a great anti-explosion performance. And hydrogen has a very high LHV than other type of fuels, especially 6.5 times as the ammonia. However, it is obvious that implementing hydrogen-based engines might not be a currently economic approach for its particularly high storage pressure at ambient temperature. As is researched that hydrogen storage process will consume almost 30\% energy more for a high storage pressure, and the storage vessels are particular heavy due to special material requirement with expensive cost.

By contrast, ammonia is potential to be transferred using steel pipelines with minor modifications thanks to its low storage pressure. Besides, ammonia can be used in combustion engines, gas turbines, burners with a high ice max compress ratio which will increase its energy density. In consequence, combustion-related properties (energy security benefits, ice max compress ratio and LHV) of the alternative fuels all led to the choice of ammonia and hydrogen as the promising alternative fuels. Gasoline and diesel have lower octane number which results in difficult for increasing the max compress ratio. Therefore, it is difficult for engines to improve the energy efficiency by increasing fuels compression ratio.

Based on combustion chemical equations, diesel has the highest air to fuel ratio by volume than other fuels, but ammonia is the smallest value among them. In other words, per unit of diesel by mass combustion consumes more air than any other fuels. In fact, the air tube is always fixed and the air volume keeps constant for practical production. So it is necessary to give an indicator that represents the mass of fuel combustion at per unit of air volume. The data in Table 2 indicates that hydrogen can provide more heat than other fuels when providing the same volume of air, and $\mathrm{CNG}$ provides the lowest amount of energy. Ammonia only generates a little bit more combustion energy than $\mathrm{CNG}$, but other conventional fuels (includes gasoline and diesel) just gives about $13 \%$ more energy than ammonia at unit cubic meters of air.

Table 1. Physical and chemical properties of vehicle fuels.

\begin{tabular}{|c|c|c|c|c|c|c|}
\hline & Ammonia & Hydrogen & CNG & Ethanol & Gasoline & Diesel \\
\hline Chemical formula & $\mathrm{NH}_{3}$ & $\mathrm{H}_{2}$ & $\mathrm{CH}_{4}$ & $\mathrm{C}_{2} \mathrm{H}_{5} \mathrm{OH}$ & $\mathrm{C}_{8} \mathrm{H}_{18}$ & $\mathrm{C}_{12} \mathrm{H}_{26}$ \\
\hline Octane number(MON) & 130 & 130 & 120 & 89.7 & 85 & -- \\
\hline Storage pressure $(\mathrm{MPa})\left(25^{\circ} \mathrm{C}\right)$ & 1.03 & $35-70$ & 25 & 1.013 & 1.013 & 1.013 \\
\hline Mass density $\left(\mathrm{kg} / \mathrm{m}^{3}\right)\left(1 \mathrm{~atm}, 15^{\circ} \mathrm{C}\right)$ & 0.771 & 0.08 & 0.65 & 809.9 & 692 & $820-850$ \\
\hline $\mathrm{LHV}(\mathrm{MJ} / \mathrm{Kg})$ & 18.61 & 121 & 50.0 & 26.9 & 43.8 & 42.5 \\
\hline Data source & {$[11][13]$} & {$[11][12]$} & {$[11][12]$} & {$[11]$} & [11] & [11] \\
\hline
\end{tabular}

Table 2. Combustion properties of vehicle fuels.

\begin{tabular}{|c|c|c|c|c|c|c|}
\hline & Ammonia & Hydrogen & CNG & Ethanol & Gasoline & Diesel \\
\hline Chemical formula & $\mathrm{NH}_{3}$ & $\mathrm{H}_{2}$ & $\mathrm{CH}_{4}$ & $\mathrm{C}_{2} \mathrm{H}_{5} \mathrm{OH}$ & $\mathrm{C}_{8} \mathrm{H}_{18}$ & $\mathrm{C}_{12} \mathrm{H}_{26}$ \\
\hline LHV (MJ/Kg) & 18.6 & 121 & 50.0 & 26.9 & 43.8 & 42.5 \\
\hline air - fuel ratio by mass & 6.14 & 34.78 & 14.39 & 6.52 & 15.26 & 15.14 \\
\hline Heat combustion of same air $\mathrm{MJ} / \mathrm{m}^{3}$ & 2.51 & 3.45 & 2.38 & 2.96 & 2.87 & 2.81 \\
\hline
\end{tabular}

\subsection{Comparative Analysis of Emissions}

Three evaluation approaches in this paper are presented for achieving emissions characteristics of all fuels. The first approach is based on the total emissions and carbon dioxide emissions produced by the same mass of air. Similarly, the second approach evaluates the total emissions by the same mass of fuels. In order to achieve comprehensive analysis of emissions properties of fuels, a calculation driven by per unit of combustion heat is required.

\subsubsection{Emissions by Same MASS of Fuels}

Figure 1 lists the data for the total emissions (including $\mathrm{CO}_{2}, \mathrm{H}_{2} \mathrm{O}$, and $\mathrm{N}_{2}$ ) generated by the same mass of fuels. It is observed that the amount of total emissions generated from 
one kilogram of fuels varies widely from alternative fuels to conventional fuels. Hydrogen generates 5 times more emissions than ammonia does, and the gap between two fuels almost equals to the difference of combustion heat. In other words, there is small difference between hydrogen and ammonia if they produce the same combustion heat. Apart from the carbon-free fuels, Ethanol produces the least emissions not only totality but also the carbon dioxide emission among hydrocarbon fuels. Figure 1 illustrates that gasoline and diesel is 2 times greater than ammonia, and ammonia is approximately $38 \%$ of methane from aspects of total exhaust emissions. In addition, the emission difference between the two fossil fuels, i.e., gasoline and diesel, is very small.

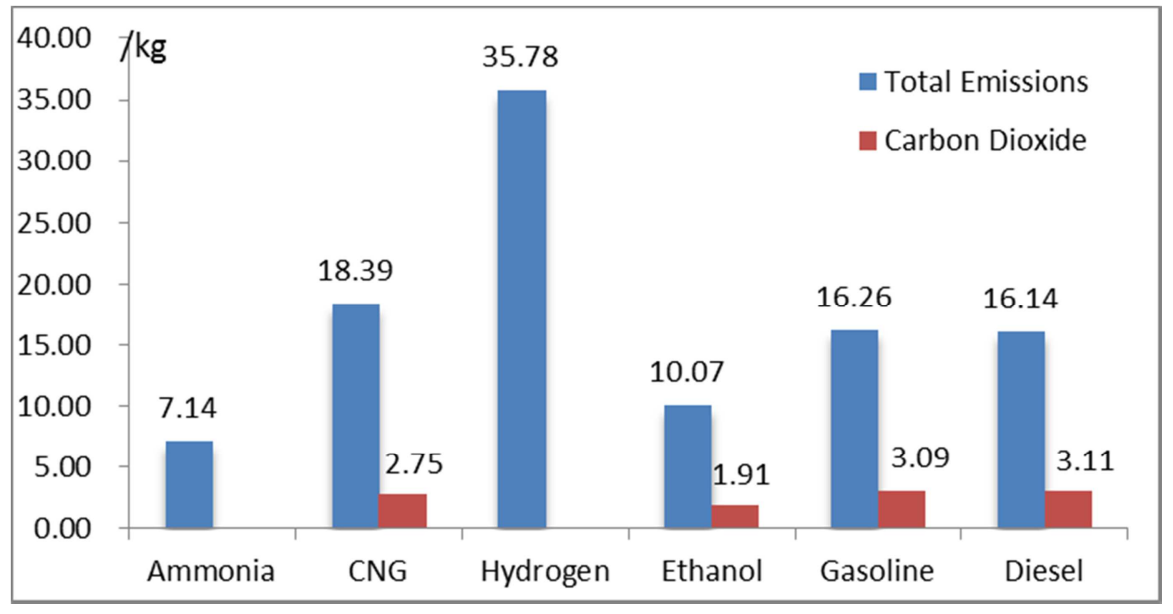

Figure 1. Exhaust emissions per unit of fuels.

\subsubsection{Emissions by Same Mass of Air}

Figure 2 displays emissions vs. different fuels with one kilogram air supply on the assumption that air-fuel ratio achieves theoretical. Proving that ammonia generates the highest emissions with 1.06 kilogram and hydrogen is the least with 1.03 kilogram emission. That is to say, hydrogen shows greater advantage of emission than others especially for ammonia. However, this is due to ammonia has the smallest theoretical air-fuel ratio, as can be seen in the Figure
2, it needs more ammonia fuel when air volume keeps constant. Carbon dioxide, the important pollutant in the exhaust gases, is not influenced by air-fuel ratio of hydrocarbon fuels. Gasoline and diesel oil have the analogous emissions whether the total emissions or the carbon dioxide. Besides, gasoline, diesel and ethanol generate the same amount of water. Nevertheless, the CNG generates fewer total exhaust gases than ethanol on account of the carbon emission distinction.

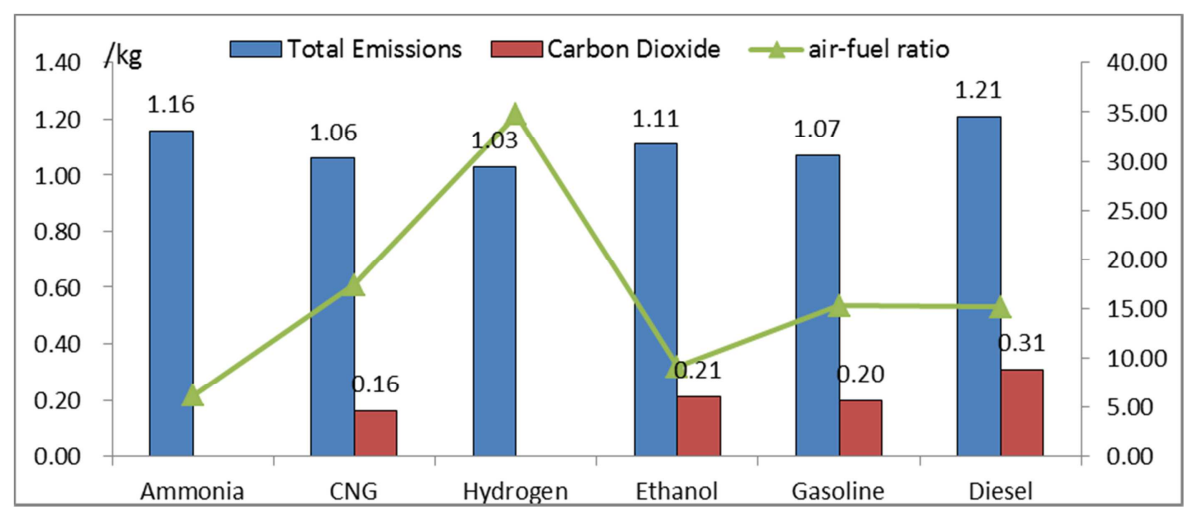

Figure 2. Emissions per unit mass of air

\subsubsection{Emissions by Same Combustion Heat}

This section compares the amount of emissions for the fuels from the aspect of same amount of combustion heat. Based on the thermodynamic calculation results illustrated in Figure 3, some interesting phenomenon can be observed. Firstly, although there is an enormous distinction in Lower Heating Value and emissions properties of different fuels, the total emissions for per unit of combustion heat shows little difference among them. Fossil fuels and ethanol all generate around $70 \mathrm{~g}$ carbon dioxide emission in order to gain $1 \mathrm{MJ}$ combustion heat. Hydrogen performs slightly better than others and it is approximately $21.0 \%$ lower than ammonia by weight. Compressed natural gas $(\mathrm{CNG})$ is the cleanest fuel in terms of carbon emissions among the four hydrocarbon fuels. However, it is proved that, from the aspect of total emissions, CNG does not show more advantages over its hydrocarbon competitors. Roughly, in order to gain the same amount of 
combustion heat, there is little difference of total emissions between fuels, however, ammonia shows the potential benefits which its production are only nitrogen and water, and they are environmentally benign chemicals and no greenhouse gasses are emitted during combustion, in contrast to fossil-fuel based transportation fuels.

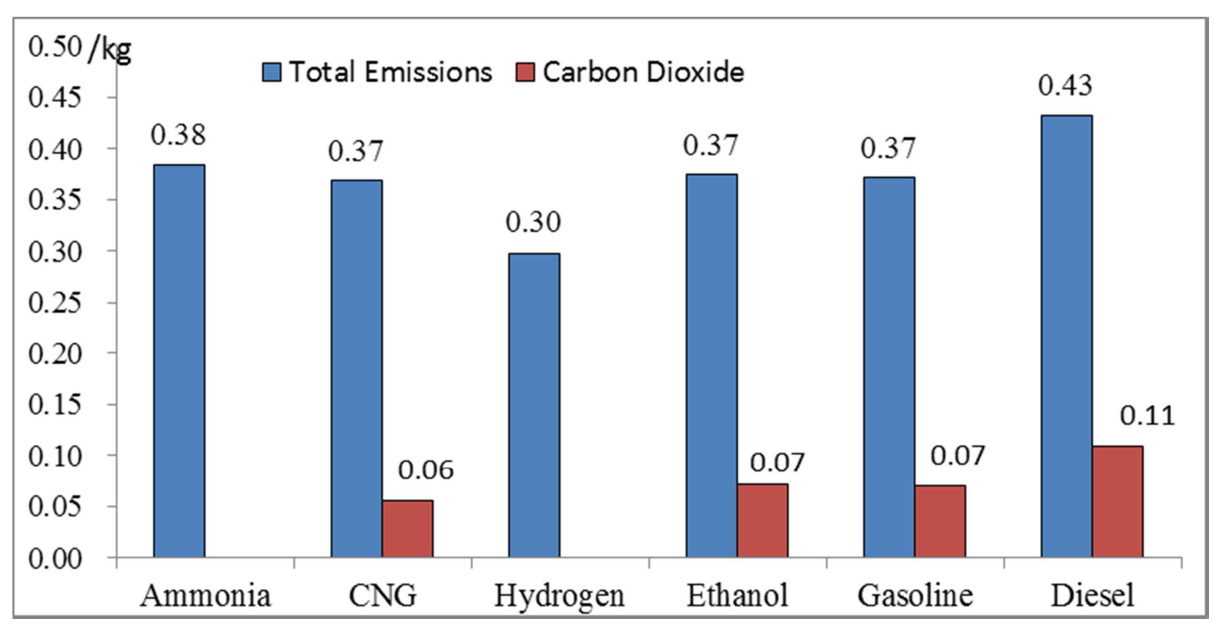

Figure 3. Total emissions per unit combustion heat.

\subsubsection{Emissions of Per Unit Combustion Heat in Dual Fuels}

There are several problems in burning ammonia because of its high auto-ignition temperature, low laminar burning speed and narrow flammability limits, but it is practical to combine ammonia with other fuels used as combustion promoters. This paper proposes hydrogen and other conventional fuels as combustion improver, and the total weight of dual fuels equals to 1 kilogram (20\% for auxiliary fuel and $80 \%$ for ammonia by weight). The emissions comparison of five blended fuel is given in Table 3. Total emissions include carbon dioxide, nitrogen and water. According to the Table 3 , it is obvious that the fossil fuels combined with ammonia have the same exhaust emission properties. The ammonia plus hydrogen generates the most combustion heat among five dual fuels, and the ammonia plus ethanol provides the least. In particular, there is no greenhouse gas providing in the exhaust emission of ammonia plus hydrogen dual fuels. In the aspects of carbon formation, the ammonia plus diesel dual fuels produce roughly as 2 times as ammonia plus ethanol which generates the least among hydrocarbon fuels with ammonia.

Table 3. Emissions of ammonia and dual fuels.

\begin{tabular}{lllll}
\hline & Combustion Heat (MJ) & Total Emissions (kg) & Carbon Dioxide (kg) & Total Emissions Density (g/MJ) \\
\hline Plus hydrogen & 39.09 & 12.87 & 0 & 329.21 \\
Plus CNG & 24.89 & 9.39 & 0.55 & 377.29 \\
Plus ethanol & 20.27 & 7.73 & 0.38 & 381.19 \\
Plus gasoline & 23.67 & 8.94 & 0.62 & 377.22 \\
Plus diesel & 23.49 & 8.86 & 0.63 & 377.04 \\
\hline
\end{tabular}

\subsection{Wasted Heat Condition and Energy Efficiency}

Combustion efficiency is one of the criterions to evaluate fuels, and it is influenced by combustion conditions, such as air equivalence ratio, combustion equipment, and heat taken away by different temperature of exhaust gas. In this paper, wasted heat of emissions is calculated at different temperature for ammonia, hydrogen and other conventional fuels. It is analyzed that the heat dissipation of different emissions temperature on the condition of the same exhausts temperature at $25^{\circ} \mathrm{C}$ degree centigrade to the wider environment finally. This paper discusses different exhaust gases temperature from 200 to $700^{\circ} \mathrm{C}$ every $100^{\circ} \mathrm{C}$ centigrade. It is on the assumption that there is no heat exchanging between $25^{\circ} \mathrm{C}$ emissions with the environment. And the water is regarded as gaseous state between 200 and $700^{\circ} \mathrm{C}$. One the one hand, this is in order to simplify the calculation, on the other hand, the gaseous state is more rational because the combustion heat is based on Lower Heat Value of fuels.
And the Lower Heat Value is measured on the assumption that water production keeps gaseous phase.

As is illustrated in Figure 5, exhaust gas takes the most heat away by per unit mass hydrogen combustion, and ammonia shows the least. Diesel and CNG reveal the same tendency at corresponding temperature and carry more energy than gasoline, ethanol and ammonia. Apparently, it is self-evident that the wasted heat of emissions shows near linear relationship with temperature for six fuels.

Table 4. Combustion efficiency at different emissions temperature.

\begin{tabular}{lllllll}
\hline Temperature & $\mathbf{2 0 0}$ & $\mathbf{3 0 0}$ & $\mathbf{4 0 0}$ & $\mathbf{5 0 0}$ & $\mathbf{6 0 0}$ & $\mathbf{7 0 0}$ \\
\hline ammonia & $91.8 \%$ & $86.9 \%$ & $81.9 \%$ & $76.9 \%$ & $71.7 \%$ & $66.4 \%$ \\
CNG & $92.8 \%$ & $88.5 \%$ & $84.1 \%$ & $79.6 \%$ & $74.9 \%$ & $70.2 \%$ \\
hydrogen & $93.5 \%$ & $89.6 \%$ & $85.7 \%$ & $81.7 \%$ & $77.5 \%$ & $73.3 \%$ \\
ethanol & $92.7 \%$ & $88.3 \%$ & $83.9 \%$ & $79.3 \%$ & $74.6 \%$ & $69.8 \%$ \\
gasoline & $92.9 \%$ & $88.7 \%$ & $84.4 \%$ & $80.0 \%$ & $75.4 \%$ & $70.8 \%$ \\
diesel & $91.7 \%$ & $86.7 \%$ & $81.6 \%$ & $76.3 \%$ & $70.9 \%$ & $65.4 \%$ \\
\hline
\end{tabular}




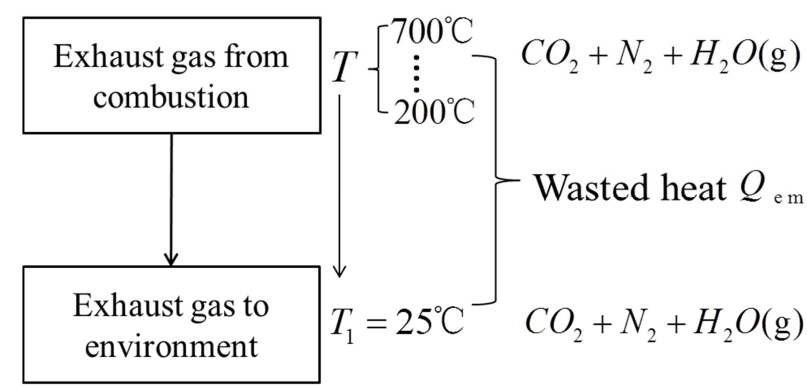

Figure 4. Heat Loss Process of Combustion Emissions.

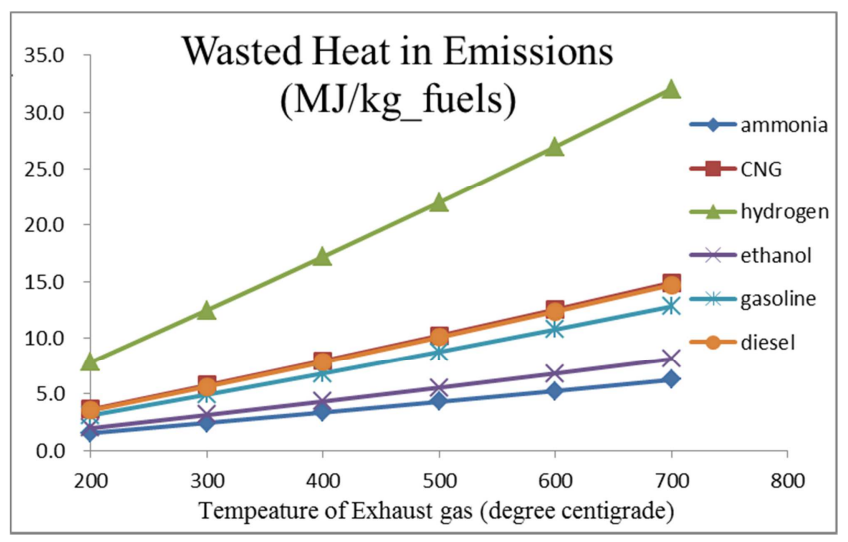

Figure 5. Energy Content of Exhaust Emissions.

It demonstrates that ammonia takes more advantage over hydrogen and other fuels when it comes to the wasted heat of emissions. However, the heat combustion of ammonia is lower than others. In this paper, energy efficiency at different emission temperature is proposed to evaluate combustion thermodynamics properties of fuels. Therefore, the result of six fuels in Table 3 is obvious, the higher temperature exhaust gases will take more wasted heat away to environment and it shows higher wasted heat to combustion heat ratio. Besides, the ratio becomes larger but non-linear with temperature increasing. According to Table3, the energy efficiency of hydrogen is highest among fuels at each temperature due to its highest LHV. On the contrary, ammonia combustion efficiency is higher than diesel although its LHV is near 2 times lower than diesel. Hydrogen and ammonia as clean alternative fuels take advantage over other conventional fuels in terms of the combustion efficiency.

\section{Conclusions}

In this study, to explore the potential of utilizing ammonia as a fuel for low carbon future energy system, combustion-related properties, emissions and combustion energy efficiency of typical fuels and ammonia were performed. Ammonia has a weakness of lower volume energy density, but it only requires a $12.5 \%$ larger fuel tank for the same amount of energy requirement than gasoline or diesel by a vehicle when a detailed physical and chemical properties comparison was firstly described. But ammonia is especially easier to be stored and transported from the aspects of pressure and temperature.

Emission characteristic results show that ammonia produces fewer emissions than hydrogen, gasoline, diesel, $\mathrm{CNG}$, and ethanol in terms of total emissions generated by per kilogram fuels. It should be noted that the emissions include $\mathrm{CO}_{2}, \mathrm{~N}_{2}$ and $\mathrm{H}_{2} \mathrm{O}$ for fossil fuel. Besides, the total emission of ammonia combustion by mass is 5 times less than hydrogen although they two are carbon-free fuels, which suggests that more combustion heat will be taken out by emissions into the atmosphere. Ammonia combustion emissions take the least heat away by the same mass of fuels, and it has higher combustion efficiency when compared to conventional diesel.

The study on the emission characteristic of dual fuel shows that hydrogen is the best combustion promoter for ammonia with no carbon dioxide emission and lowest total emissions at the same combustion heat. However, calculation results show that ethanol is not appropriate as promoter fuel for ammonia. Also, gasoline and diesel have higher carbon dioxide emissions, which imply the feasibility of using ammonia and hydrogen as primary dual fuel with the advantage of less emissions and higher combustion energy.

As a result, ammonia is a very promising alternative fuel and has advantages over hydrogen and other conventional fossil fuels.

\section{References}

[1] Haputhanthri, S. O., Austin, C., Maxwell, T., and Fleming, J., "Ammonia and Gasoline Composite Liquid Fuel Blends Emulsified with Ethanol and Methanol for Direct Displacement in Internal Combustion Engines," IOSR J. Mech. Civil Eng., vol. 11, 2014, pp. 11-18.

[2] Chintala, V. and K. A. Subramanian, "A comprehensive review on utilization of hydrogen in a compression ignition engine under dual fuel mode." Renewable and Sustainable Energy Reviews, vol. 70, 2017, pp. 472-491.

[3] Tsujimura, T. and Y. Suzuki, "The utilization of hydrogen in hydrogen/diesel dual fuel engine. International Journal of Hydrogen Energy.” International Journal of Hydrogen Energy, vol. 11, 2017, pp. 1-11.

[4] Du, Y., et al., "Effect of addition of hydrogen and exhaust gas recirculation on characteristics of hydrogen gasoline engine." International Journal of Hydrogen Energy, 2017, pp. 1-11.

[5] Liu R, Ting D S, Checkel MD. "Ammonia as a fuel for SI engine.” Training, 2013, pp. 11.

[6] Stark man ES, Newhall H K, Sutton R, et al. "Ammonia as a spark ignition engine fuel: theory and application." Challenge, vol. 3,2009 , pp. 25

[7] Frigo, S. and R. Gentili, "Analysis of the behaviour of a 4-stroke Si engine fuelled with ammonia and hydrogen." International Journal of Hydrogen Energy, vol. 38, 2013, pp. $1607-1615$.

[8] Reiter AJ, Kong SC. "Combustion and emissions characteristics of compression ignition engine using dual ammonia diesel fuel.” Fuel, vol. 90, 2011, pp. 87 97. 
[9] Duynslaegher, C., et al., "Modeling of ammonia combustion at low pressure. "Combustion and Flame, vol. 159, 2012, pp. 2799-2805.

[10] Nozari, H. and A. Karabeyoğlu, "Numerical study of combustion characteristics of ammonia as a renewable fuel and establishment of reduced reaction mechanisms." Fuel, vol. 159, 2015, pp. 223-233.

[11] Data source: Bill Leighty,"comparing fuels for energy transmission, storage, and integration", San Antonio, ammonia fuel conference, vol. 10, 2012, pp. 2.
[12] Barthelemy, H., M. Weber, and F. Barbier, Hydrogen storage: Recent improvements and industrial perspectives. International Journal of Hydrogen Energy, 2017. 42(11): p. 7254-7262.

[13] Catherine Duynslaegher. "Experimental and numerical study of ammonia combustion." University of Leuven, 2011, pp. $1-314$.

[14] D. Hotza, J. D. da Costa, Int. J. Hydrogen Energy, vol. 33, 2008, pp. 4915-4935.

[15] Weidao Shen, Jungeng Tong, Engineering Thermodynamics, Higher education press, 2007, pp. 441. 